\title{
Aortic flow and wall shear stress in aortic stenosis is associated with left ventricular remodeling
}

Florian von Knobelsdorff-Brenkenhoff ${ }^{*}$, Achudhan Karunaharamoorthy ${ }^{1}$, Ralf F Trauzeddel ${ }^{1}$, Alex J Barker ${ }^{2}$, Edyta Blaszczyk ${ }^{1}$, Michael Markl2,3, Jeanette Schulz-Menger ${ }^{1}$

From 19th Annual SCMR Scientific Sessions

Los Angeles, CA, USA. 27-30 January 2016

\section{Background}

Aortic stenosis (AS) can lead to highly variable stress for the left ventricle (LV) and consequently a broad range of LV remodeling. We hypothesize that changes in aortic blood flow caused by AS can contribute to cardiac afterload. The aim of this study was to describe the blood flow patterns in the ascending aorta in patients with AS and to determine its association with LV remodeling.

\section{Methods}

Thirty-seven patients with AS (14 mild, 8 moderate, 15 severe, age $63 \pm 13$ years) and 37 healthy, age- and gendermatched controls (age $60 \pm 10$ years) were prospectively

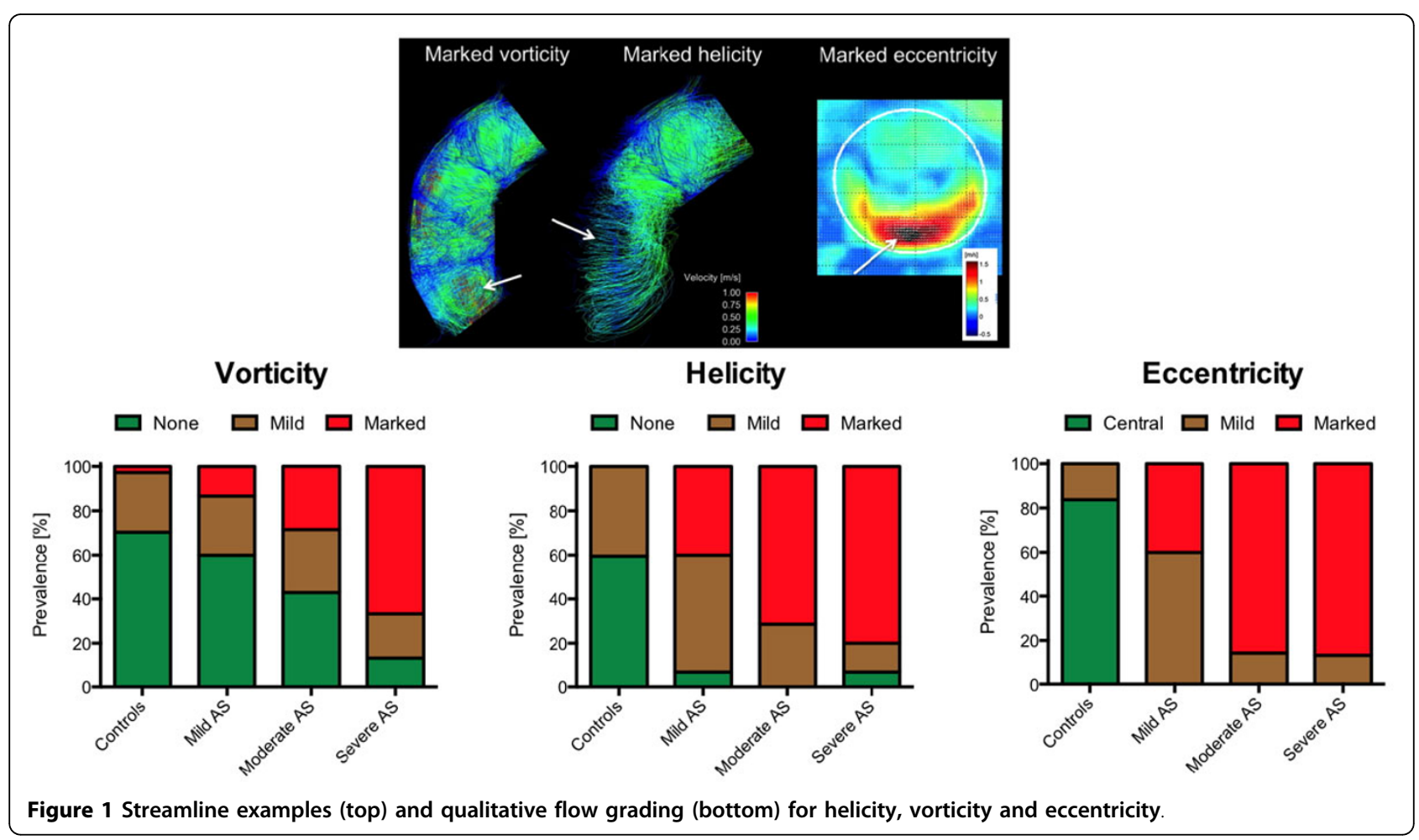

${ }^{1}$ Charité Medical Faculty and HELIOS clinics, Working group Cardiovascular

MRI, Berlin, Germany

Full list of author information is available at the end of the article 


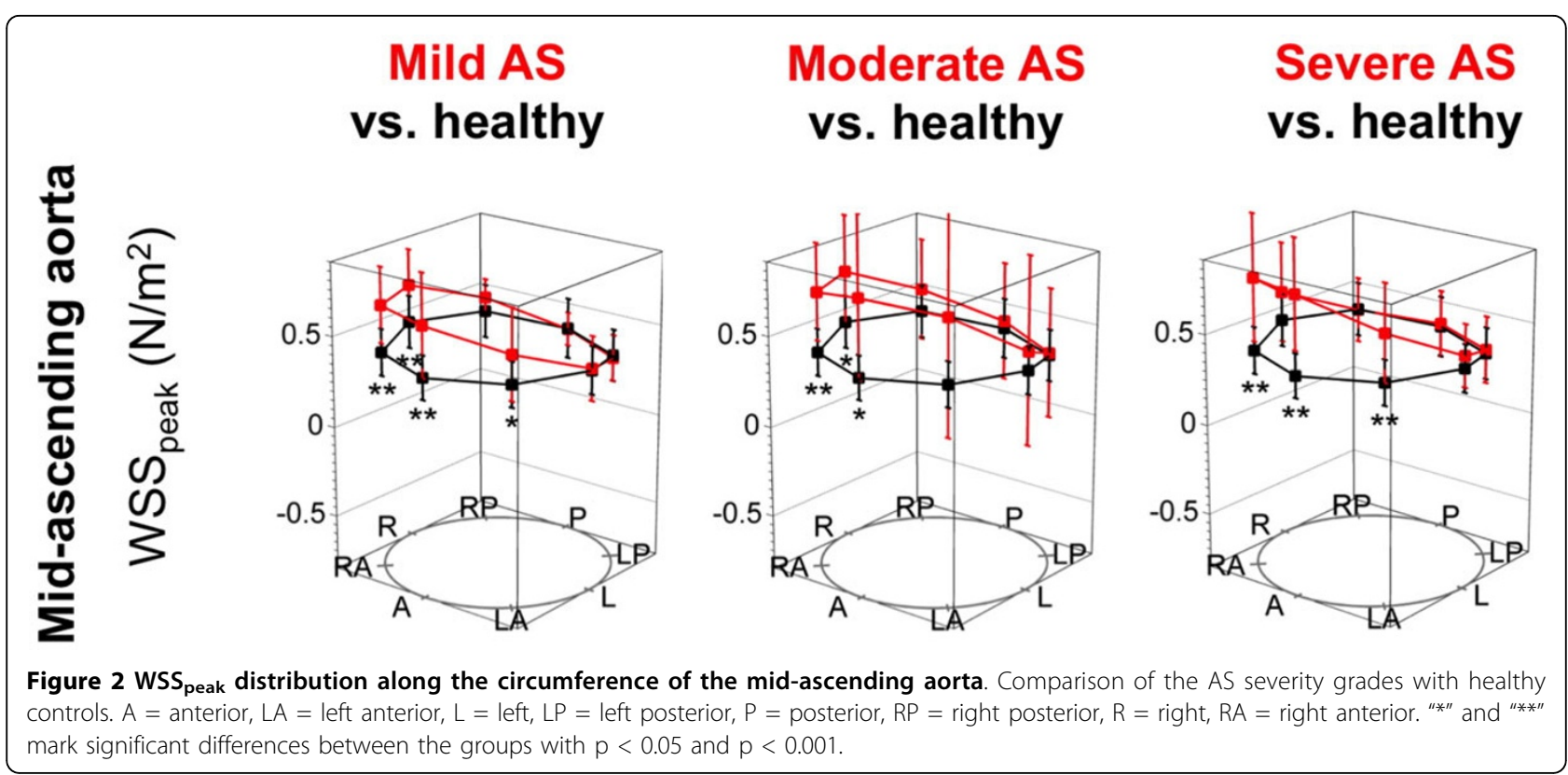

enrolled to undergo 4D-flow MRI of the aorta. Vorticity and helicity were graded as absent, mild or marked using time-resolved 3D pathlines. Eccentricity of the peak blood flow velocity was evaluated as absent, mild or marked using a 2D plane in the mid-ascending aorta, and flow displacement from the vessel center was calculated. Peak systolic

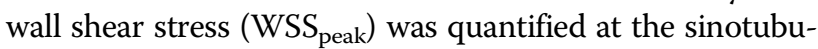
lar level, mid-ascending and distal ascending aorta. LV remodeling was defined as increased ratio of LV mass by enddiastolic volume (relative wall mass, RWM).

\section{Results}

The prevalence of helicity, vorticity and eccentricity was significantly higher in AS than in controls (Figure 1). In AS, aortic orifice area correlated significantly with the extent of eccentricity $(r=-0.48 ; p=0.003)$ and vorticity $(\mathrm{r}=-0.52 ; \mathrm{p}=0.001)$, and RWM correlated significantly with helicity, vorticity and eccentricity $(r=0.48$, $\mathrm{r}=0.60, \mathrm{r}=0.49$; each $\mathrm{p}<0.001$ ). Patients with LV remodeling exhibited significantly higher normalized flow displacement than patients without LV remodeling $(0.19 \pm 0.05$ vs. $0.15 \pm 0.04 ; p=0.034)$. WSS peak $_{\text {was }}$ significantly elevated compared to controls in all severity grades of AS, with asymmetric peaks at the right and anterior curvature at the sinutubular level and in the mid-ascending aorta (Figure 2). There was no difference in $\mathrm{WSS}_{\text {peak }}$ levels between patients with and without LV remodeling.

\section{Conclusions}

AS leads to significantly abnormal vorticity, helicity and eccentricity as well as WSS $_{\text {peak }}$ distribution in the ascending aorta. LV remodeling correlated with the extent of abnormal blood flow.

\section{Authors' details}

${ }^{1}$ Charité Medical Faculty and HELIOS clinics, Working group Cardiovascular MRI, Berlin, Germany. ${ }^{2}$ Department of Biomedical Engineering, McCormick School of Engineering, Northwestern University, Chicago, IL, USA. ${ }^{3}$ Department of Radiology, Medical Physics, Feinberg School of Medicine, Northwestern University, Chicago, IL, USA.

Published: 27 January 2016

doi:10.1186/1532-429X-18-S1-Q57

Cite this article as: von Knobelsdorff-Brenkenhoff et al: Aortic flow and wall shear stress in aortic stenosis is associated with left ventricular remodeling. Journal of Cardiovascular Magnetic Resonance 2016 18(Suppl 1):Q57.

Submit your next manuscript to BioMed Central and take full advantage of:

- Convenient online submission

- Thorough peer review

- No space constraints or color figure charges

- Immediate publication on acceptance

- Inclusion in PubMed, CAS, Scopus and Google Scholar

- Research which is freely available for redistribution 